\title{
Epigenetic control of gonadotropin releasing hormone
}

\section{neurons}

\author{
Joseph R. Kurian ${ }^{1}$ and Ei Terasawa ${ }^{1,2}$ \\ ${ }^{1}$ Wisconsin National Primate Research Center, University of Wisconsin-Madison, Madison, WI, USA \\ ${ }^{2}$ Department of Pediatrics, School of Medicine and Public Health, University of Wisconsin, Madison, WI, USA
}

\section{Edited by:}

Pei-San Tsai, University of Colorado, USA

\section{Reviewed by:}

Sergio R. Ojeda, Oregon Health \&

Science University, USA

Toni R. Pak, Loyola University

Chicago, USA

*Correspondence:

Joseph R. Kurian, Wisconsin National

Primate Research Center, University

of Wisconsin-Madison, 1220 Capitol

Ct, Madison, WI 53705, USA.

e-mail: jrkurian@wisc.edu
Epigenetic modifications to the genome, including DNA methylation and histone modifications, occur in response to external stimuli. Reproductive function is highly sensitive to environmental conditions including season, diet, hormonal changes, and exposure to chemical contaminants. GnRH neurons, which play a key role in reproduction, are particularly sensitive to various environmental stimuli. We recently reported that the rhesus monkey $\mathrm{GnRH}$ gene exhibits distinct epigenetic changes during embryonic development. More recently, we further found that a similar epigenetic phenomenon occurs across puberty. In this article we highlight recent findings, including those of afferent inputs, to describe the epigenetic control of $\mathrm{GnRH}$ circuit development as a link between the environment and reproductive function.

Keywords: gonadotropin releasing hormone, kisspeptin, reproduction, puberty, neuroendocrine, epigenetic, histone, methylation

\section{INTRODUCTION}

Epigenetic mechanisms are responsible for the tremendous diversity among cell phenotype and function. These mechanisms establish intricate patterns of modifications to DNA and histones, which subsequently control gene expression profiles. Because epigenetic modifications are sensitive to external stimuli, they provide a means for cellular adaptation to environmental pressures. Given the sensitivity of neuroendocrine systems to environmental conditions, significant interest has grown over the epigenetic control of neuroendocrine function.

The past decade has seen an explosion of neuroendocrine epigenetic research, primarily yielding patterns of DNA methylation and histone modifications. To date, how these patterns are established and whether those patterns are critical to neuroendocrine function remains mostly a mystery. However, three reports (Kurian et al., 2010; Iyer et al., 2011; Lomniczi et al., 2013) have recently described epigenetic differences that seem critical to development of the GnRH neuronal circuit, and more importantly appear to pinpoint mechanisms responsible for those epigenetic phenomena. This review synthesizes the findings of those reports to illustrate the promising future of epigenetic research in reproductive neuroendocrine function.

\section{DNA METHYLATION IN GnRH NEURONS}

The GnRH neuron is a critical relay in the axis controlling reproductive function. Specifically, its ability to release sufficient, episodic pulses of GnRH peptide into the pituitary portal circulation is essential for gametogenesis in both sexes and ovulation in females. While upstream mechanisms fine-tune GnRH neuronal activity, GnRH neurons also have an intrinsic capacity to release GnRH peptide in a pulsatile manner.

GnRH neurons reside in the preoptic area and base of the hypothalamus, among a complex milieu of other neurons and glia; this presents a challenge for studying the cellular and molecular mechanisms of neuronal differentiation and function. Fortunately, the unique ontogeny of $\mathrm{GnRH}$ neurons provides an opportunity to isolate a GnRH neuronal population for in vitro studies. In the rhesus monkey, these neurons differentiate from progenitor cells in the nasal placode between embryonic (E) days 32-34 (Ronnekleiv and Resko, 1990; Quanbeck et al., 1997). GnRH neurons subsequently begin migrating into the brain at about E36 and settle down in the hypothalamus by E55 (Terasawa et al., 2001). Isolating the nasal placode after E34 but prior to migration provides a neuronal population that consists of entirely GnRH neurons. We found that placode tissue isolated on E36 developed typical patterns of mature activity (e.g., GnRH peptide release; Terasawa et al., 1993, 1999; Kurian et al., 2010) after about 2 weeks in vitro. Wray and colleagues, who developed a similar murine in vitro culture model (Fueshko and Wray, 1994), have also reported a period of gradual maturation after isolation from the nasal placode (Constantin et al., 2009). In addition, they report that development of GnRH peptide release patterns is paralleled by increasing $\mathrm{GnRH}$ gene expression and peptide biosynthesis (Maurer and Wray, 1997; Moore and Wray, 2000). A question arises. What mechanism triggers increasing gene expression during GnRH neuronal development?

The genetic control of GnRH gene expression is well characterized and depends on several cis sequences in the $5^{\prime}$ region of the gene. The rat gene contains a neuron specific enhancer region between -1863 and -1571 (Kepa et al., 1992, 1996b; Clark and Mellon, 1995; Whyte et al., 1995). This spans a major region of homology between the rat $(-1786$ to -1559$)$ and human $(-2766$ to -2539$)$ genes. Interestingly, this portion of the human gene does not appear to enhance gene expression; in fact, based on serial truncations of the $5^{\prime}$ human GnRH gene in luciferase assay constructs, it appears that this region impedes enhanced 
gene expression (Kepa et al., 1996a). Importantly, this area has sequence similarity to a $5^{\prime}$ portion of the rhesus monkey GnRH gene. We noticed that this distal $5^{\prime}$ region of the rhesus monkey gene (Figure 1) contains a 243-bp segment (-2126 to -1863) that has $60 \%$ GC content and a CpG (cytosine-guanine) dinucleotide observed to expected ratio of 0.65 ( $14 \mathrm{CpG}$ sites). These characteristics define the region as a CpG island (CGI; Gardiner-Garden and Frommer, 1987). CGIs, when associated with gene promoters, are related to the epigenetic regulation (DNA methylation) of gene expression (Deaton and Bird, 2011).

DNA methylation is the covalent addition of a methyl $\left(-\mathrm{CH}_{3}\right)$ group to nucleotides. Mammalian DNA-methyltransferase (DNMT) enzymes catalyze this reaction, primarily at the $5^{\prime}$ carbon of cytosines in $\mathrm{CpG}$ dinucleotides. There are three primary DNMT enzymes (1,3a, and $3 \mathrm{~b})$, each critical to development as demonstrated by embryonic or early postnatal lethality in monogenic null mouse models (Li et al., 1992; Okano et al., 1999). DNMT1 is responsible for faithful maintenance of DNA methylation after replication through cell division (Bestor and Ingram, 1983; Bestor et al., 1988; Hermann et al., 2004). DNMTs 3a and $3 \mathrm{~b}$ are de novo methyltransferases responsible for newly acquired methylation such as during the initial establishment of methylation patterns during early embryonic development (Okano et al., 1998, 1999). Once established, DNA methylation can have several impacts on gene transcription. Methylated DNA can directly alter transcription factor recognition of cis sequences or attract methyl-binding proteins thereby blocking genomic locations from transcription factor assembly. In addition, methyl-binding proteins (e.g., MeCP2, Mbd2, Kaiso) interact with histone modifying factors to alter chromatin structure.

Until our recent studies (Kurian et al., 2010), there were no reports of the epigenetic aspects of $\mathrm{GnRH}$ neuron maturation or function. The CGI in the $5^{\prime}$ region of the rhesus monkey $G n R H$ gene was suggestive to us that DNA methylation has some role in neuronal function. We hypothesized that increasing peptide release during in vitro maturation of $\mathrm{GnRH}$ neurons would be related to increased gene expression and changing DNA methylation patterns across the rhesus monkey GnRH gene, particularly within the 5'CGI. As suspected, we found that GnRH mRNA levels were low at day 0 but rose dramatically by day 20 of in vitro cultures. This increase was paralleled by a dramatic decrease in CpG

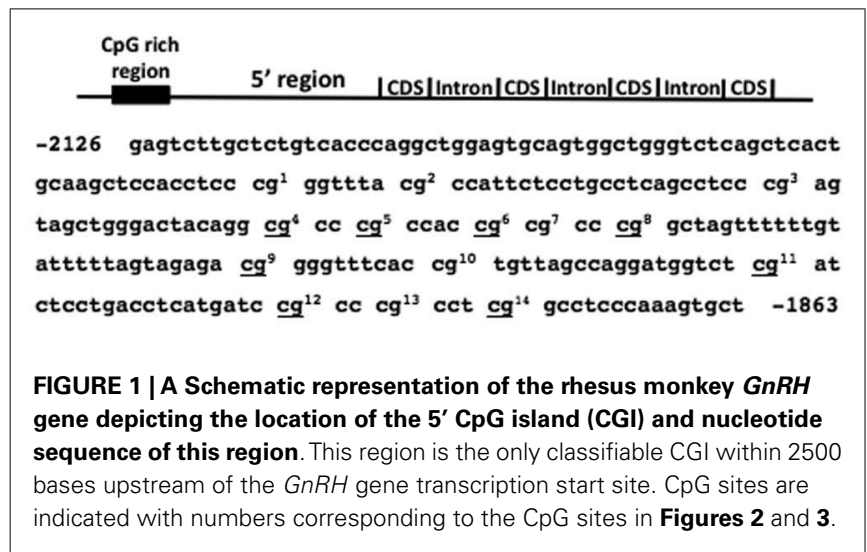

methylation status in the $5^{\prime}$ CGI (Figure 2). We also found that a comparable phenomenon occurs across puberty. Similar to the previous observation by Plant and colleagues showing that $\mathrm{GnRH}$ mRNA levels increase between juvenile and pubertal stages in the medial basal hypothalamus $(\mathrm{MBH})$ of orchidectomized male rhesus monkeys (El Majdoubi et al., 2000), we also observed that $\mathrm{GnRH}$ mRNA levels increase in the male $\mathrm{MBH}$ across puberty (Figure 3). Furthermore, methylation status of the $5^{\prime}$ CGI of the $G n R H$ gene was lower in adult compared to prepubertal male rhesus monkeys (Figure 3; Kurian et al., 2011). This suggests to us that developmental rises in GnRH gene expression are at least partly the result of DNA demethylation across a CGI in the GnRH gene.

When evaluating these findings, it is important to consider the distinct pattern of GnRH neuronal activity across development. In primates, GnRH release is elevated, as indicated by

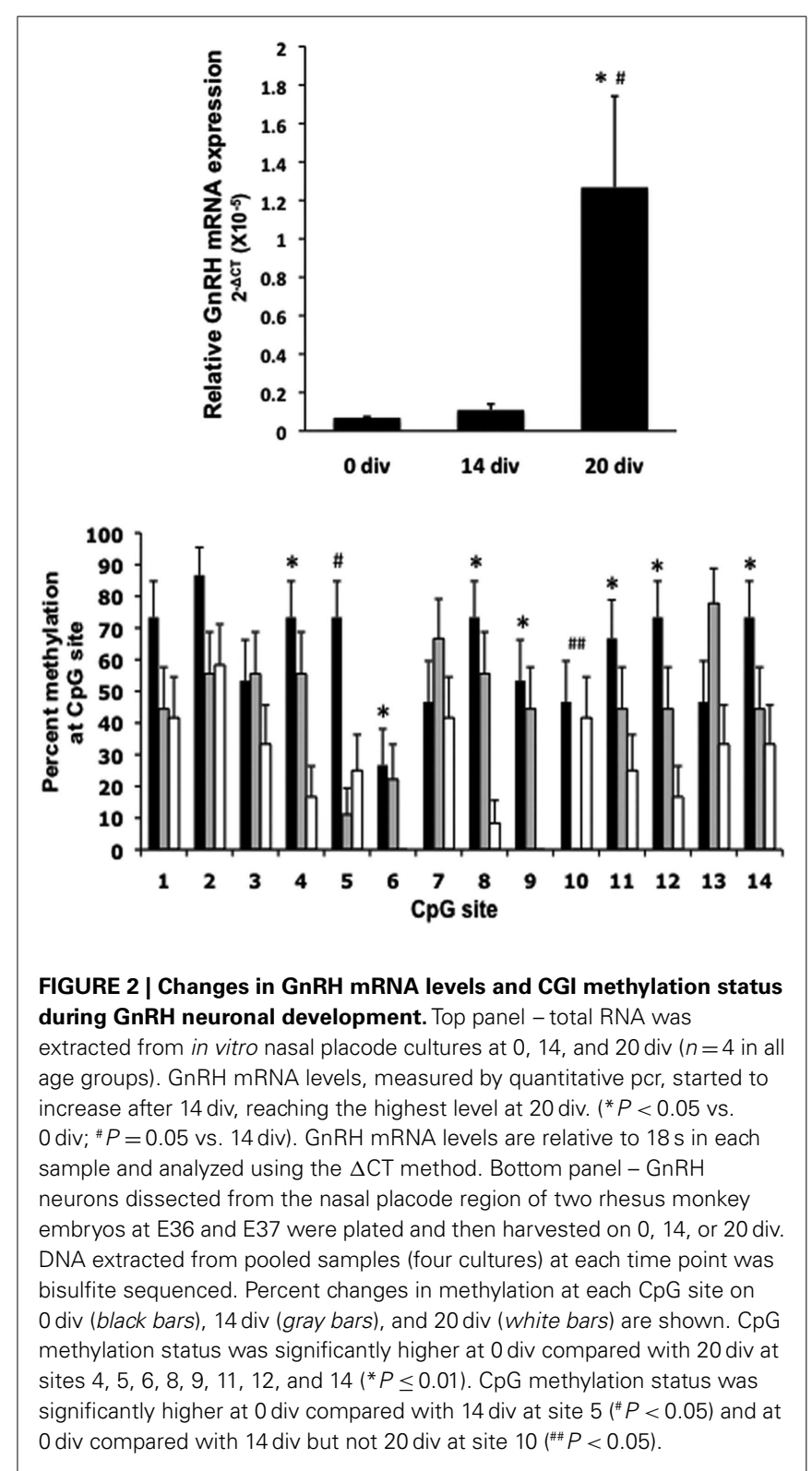




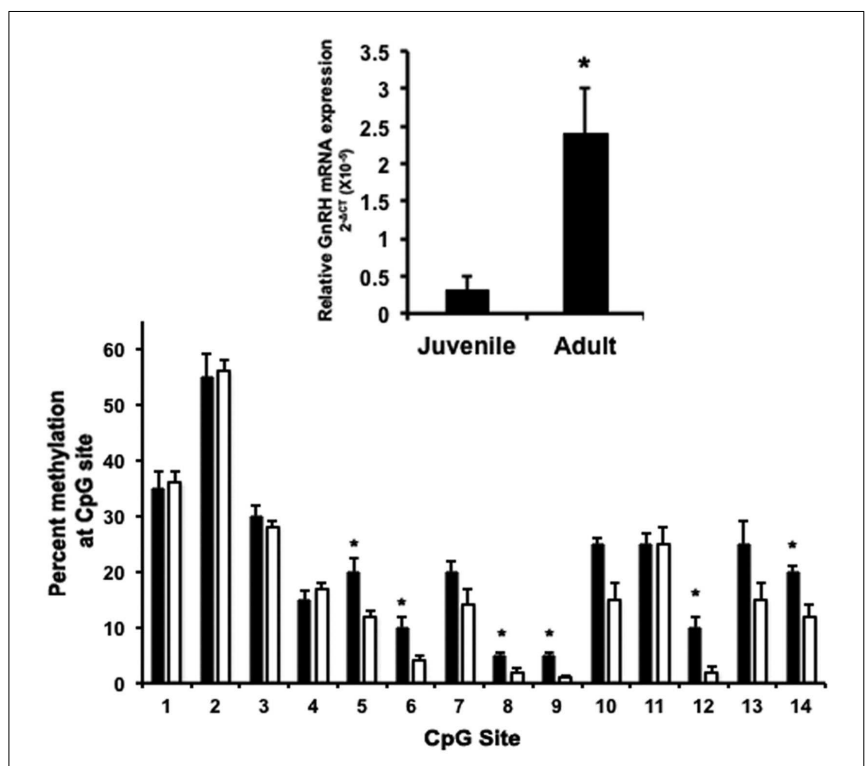

FIGURE 3 | Changes in GnRH mRNA levels and CGI methylation status across puberty in male rhesus monkey medial basal hypothalamic (MBH) tissue. Top panel - total RNA and DNA was extracted from MBH tissue of juvenile ( $n=3$, mean age $22.7 \pm 2.8$ months) and adult ( $n=5$, mean age of $110 \pm 23.4$ months) rhesus monkeys. GnRH mRNA levels, measured by quantitative PCR, were higher in adult compared to juvenile $\mathrm{MBH}\left({ }^{*} P<0.05\right)$. GnRH mRNA levels are relative to $18 \mathrm{~s}$ in each sample and analyzed using the $\triangle \mathrm{CT}$ method. Bottom panel - DNA extracted from the same samples was bisulfite sequenced. Percent changes in methylation at each $\mathrm{CpG}$ site for juvenile (black bars) and adult (white bars) $\mathrm{MBH}$ tissue are shown. CpG methylation status was significantly higher in juvenile compared to adult $\mathrm{MBH}$ samples sites $5,6,8,9,12$, and $14\left({ }^{*} P \leq 0.05\right)$.

peripheral luteinizing hormone levels, during a brief perinatal period, but then decreases during juvenile development before gradually increasing again through puberty. Our findings suggest that each period of elevated GnRH release is related to demethylation of the $G n R H$ gene CGI. Specifically, in vitro maturation is representative of embryonic development leading to elevated activity during the perinatal period while measurements in $\mathrm{MBH}$ tissue are indicative of developmental changes across pubertal maturation. The decrease in methylation status across puberty is indicative of two potential scenarios. One possibility is that the process initiated in embryonic development might stall during the juvenile period and subsequently resume at puberty onset. Alternatively, the CGI may become re-methylated during juvenile development, and again demethylated at puberty onset. The latter scenario would suggest that lower CpG methylation status must be maintained to enable elevated GnRH gene expression. Consequently, a mechanism responsible for DNA demethylation and perhaps another mechanism responsible for maintaining hypomethylated DNA might both be necessary for the transition to puberty and maintenance of reproductive function. A comparison of $\mathrm{CpG}$ methylation status between perinatal and early pubertal $\mathrm{MBH}$ tissue will be necessary to differentiate between these two scenarios. Nonetheless, our current findings suggest that DNA demethylation is an important aspect of $\mathrm{GnRH}$ neuronal development and function.

\section{ACTIVE DNA DEMETHYLATION IN GnRH NEURONS}

Given the postmitotic/non-dividing state of GnRH neurons in our in vitro cultures and across the pubertal transition measured in $\mathrm{MBH}$ samples, the process of DNA demethylation we discovered must be active. The mechanisms responsible for active DNA demethylation are not well characterized, and until recently skepticism has remained over the existence of this process in mammalian systems.

DNA demethylation is achieved via two general mechanisms, passive or active. Passive demethylation occurs through cell divisions and interruption of maintenance methyltransferase activity. Current pharmaceutical approaches for DNA demethylation target this mechanism. For example, 5-azacytidine (5-aza) is metabolized and subsequently incorporated into DNA, where it then acts as a substrate that covalently traps DNMTs after methyl transfer to the 5-aza nitrogen (Schermelleh et al., 2005; Svedruzic, 2008). Active demethylation is not well characterized. Several mechanisms are proposed, and intense efforts to validate or better characterize these mechanisms continue. For thorough background, we suggest a recent review (Wu and Zhang, 2010) that outlines several promising pathways discovered during the past decade. Presently, a well accepted mechanism is the sequential enzymatic process beginning with oxidation of 5-methylcytosine $(5 \mathrm{mC})$ to 5 -hydroxymethylcytosine $(5 \mathrm{hmC})$, which is carried out by any one of three ten-eleventranslocation enzymes (Tet $1-3$ ). $5 \mathrm{hmC}$ is a stable epigenetic modification, though under certain circumstances it is recognized and excised by thymine DNA glycosylases. Base excision repair subsequently completes the transition. Importantly, brain tissue, and particularly the hypothalamus, has the highest reported 5-hydroxymethylcytosine $(5 \mathrm{hmC})$ tissue abundance (Branco et al., 2012). In addition, we recently reported that increasing expression of Tet 1 and Tet 2 across neuronal maturation could influence GnRH gene expression (Kurian and Terasawa, 2012).

Emerging physiological evidence also supports a role for Tet enzymes in neuroendocrine development, and particularly the control of reproductive function. For example, Tet1 knock out mice exhibit deficits in fecundity. This effect is primarily a female specific abnormality, as typical litter sizes result from crossing wild-type females with Tet1 knockout males, whereas wild-type males mated to Tet 1 knockout females produces significantly fewer offspring per litter (Dawlaty et al., 2011). A subsequent report suggests this defect in fecundity might be the consequence of abnormal progression of female germ cell development through the second meiotic division prior to ovulation (Yamaguchi et al., 2012). Interestingly, stimulation of the second meiotic division and ovulation requires a GnRH driven LH surge (Mehlmann, 2005). Consequently, given the apparent active DNA demethylation associated with GnRH neuronal development, the effect of Tet depletion on abnormal reproductive function might be the consequence of altered Tet mediated epigenetic differentiation in the neuroendocrine hypothalamus. While hypothalamic expression patterns of Tet enzymes are not yet reported, cortical neuron expression is restricted to Tet 2 and Tet3 (Hahn et al., 2013). That this deficit in fecundity was even more pronounced in double knockout (Tet1 and Tet2 knockout) mice (Dawlaty et al., 
2013) gives further credence to the suggestion that Tet enzymes are active in the hypothalamus to promote neuronal maturation toward stage specific reproductive function.

As the mechanisms responsible for active demethylation in GnRH neurons are discovered, the ultimate goal will be to characterize how environmental factors influence those epigenetic changes. It should be noted that GnRH neurons experience dramatic shifts in environment during their development and migration. In addition to traveling through or near several tissue types, GnRH neurons are subjected to changing growth factor, chemokine and neurotransmitter levels, some of which form gradients between the nasal region and forebrain (reviewed by Wray, 2010). How these shifts in environment alter the epigenetic landscape in GnRH neurons is yet to be defined, though this background may prove instrumental to the characterization of epigenetic mechanisms pertinent to GnRH neuron maturation.

\section{HISTONE MODIFICATIONS IN GnRH NEURONAL FUNCTION}

Histones are an integral component of nucleosomes, the primary units for genome organization or compaction. Consequently, these proteins, through interaction with DNA, have a critical role in determining gene expression patterns. There are four primary classes of histones, 1 through 4 . Histones 2 through 4 are components of the core octamer, which DNA circumnavigates in about 146 base pairs to form a single nucleosome. Histone 1 is a scaffold protein, which tightly packages nucleosomes when present. Several variants of this histone are distinguishable by sensitivity to hormones (Banks et al., 2001). Histone 2 also has several variants including $\mathrm{A}, \mathrm{AX}$, and $\mathrm{B}$. Histone $2 \mathrm{AX}$ is particularly intriguing in the context of neuronal maturation (Lee et al., 2010) and function based on its association with activity dependent DNA double strand breaks in neurons (Suberbielle et al., 2013). Histones 3 and 4 complete the nucleosome octamer with histone 3 the most heavily investigated in the realm of neuroendocrine function. Histone 3 has two variants, $\mathrm{H} 3.3 \mathrm{~A}$ and $\mathrm{H} 3.3 \mathrm{~B}$. These variants are integral to DNA replication independent histone switching, which would be presumed an important mechanism in regulation of post mitotic cell activity. To date, to our knowledge, nothing is reported regarding the relationship between histone switching and hypothalamic neuronal maturation or function.

Histone proteins package DNA largely due to their predominant positive charge attracting negatively charged DNA. Posttranslational modifications (PTMs) alter the strength of that attraction, and recruit or repel transcriptional machinery and histone modifying enzymes. Consequently, these PTMs alter gene accessibility and rates of transcription. Several known modifications include acetylation, phosphorylation, methylation, ubiquitination, sumoylation, and glcnacylation. To date, measurements of histone PTMs in neuroendocrine systems have focused on acetylation and methylation. Acetylation leaves a more negative charge on histones and consequently promotes transcription. Methylation is neutral, and depending on the location and degree (mono, di, or tri-methylation), can either promote or inhibit transcription.

Mellon and colleagues were the first to report a pattern of permissive histone modifications enabling elevated or mature $\mathrm{GnRH}$ gene transcription (Iyer et al., 2011). Their studies capitalized on the distinct stages of development between two GnRH neuronal cell lines. GN11 cells, originally isolated from a tumor in the mouse nasal placode (Radovick et al., 1991), express GnRH at very low levels, whereas GT1 cells, which were isolated from an analogous tumor in the mouse hypothalamus (Mellon et al., 1990), are characterized by mature activity patterns including elevated GnRH gene expression ${ }^{1}$. In essence, comparisons between these two cell lines are similar to our evaluations of embryonic nasal placode derived neurons from days 0 and 20 in vitro described above. They found that the GnRH gene promoter and enhancer regions in immature GN cells were more heavily associated with a repressive histone modification: histone 3 (H3) lysine 9 (K9) di-methylation (me2). On the other hand, the same genomic regions in GT1 cells were associated with the permissive $\mathrm{H} 3 \mathrm{~K} 9$ acetylation and H3K4me3 PTMs. For comparison, they also evaluated these histone PTM patterns in a non-neuronal (NIH3T3) cell line. The repressive PTMs were high in NIH3T3 cells, intermediate in GN cells and low in GT1 cells. The presence of permissive PTMs was low and similar between NIH3T3 and GN cells but significantly higher in mature GT1 cells.

\section{TRANSACTIVATION OF BIVALENT DOMAINS IN REPRODUCTIVE NEUROENDOCRINE FUNCTION}

The intermediate repressive chromatin state in GN cells is indicative of a bivalent promoter, where both repressive and permissive histone PTMs maintain genes in a repressed albeit primed position. These chromatin domains were first described in embryonic stem (ES) cells and associated with developmentally regulated transcription factors (Azuara et al., 2006; Bernstein et al., 2006; Pan et al., 2007). Several recent reports, taken together, indicate that establishment of bivalent domains through polycomb repressive complex 2 (PRC2) and mixed lineage leukemia (MLL) is critical for neural lineage differentiation from ES cells (Yu et al., 1995; Yagi et al., 1998; Glaser et al., 2006; Pasini et al., 2007; Shen et al., 2008). The PRC2 component, Ezh2, is responsible for $\mathrm{H} 3 \mathrm{~K} 27$ methylation, which is subsequently bound by the PRC1 complex to maintain tri-methylation at H3K27. MLL methylates $\mathrm{H} 3 \mathrm{~K} 4$. Together, these complexes are proposed to establish a bivalent promoter, with the heavily repressive $\mathrm{H} 3 \mathrm{~K} 27 \mathrm{me} 3$ mark in close proximity to $\mathrm{H} 3 \mathrm{~K} 4 \mathrm{me}$. Interestingly, this particular bivalent domain appears related to the juvenile repression and subsequent activation of kisspeptin gene expression during the pubertal transition in female rats (Lomniczi et al., 2013). As a major stimulant of $\mathrm{GnRH}$ release, this epigenetic regulation of kisspeptin expression may be instrumental in development of the mature GnRH neuronal circuit.

\footnotetext{
${ }^{1}$ The developmental differences in the original GnRH cell lines (GN and GT1) might be the consequence of typical epigenetic differentiation in the $5^{\prime}$ portion of the GnRH gene. Each cell line was derived with a different portion of the GnRH gene promoter driving SV40 expression/tumor initiation. GN cells were generated using a short portion of the human GnRH promoter, which resulted in early tumor production in the placode region, presumably shortly after differentiation from precursor cells. On the other hand, GT1 cells were derived from hypothalamic tumors in animals that expressed SV40 driven by a longer $5^{\prime}$ portion of the rat promoter. This longer promoter contains higher CpG content than the short human promoter used for GN cell generation. Consequently, similar to our proposal that the distal $5^{\prime}$ region of the GnRH gene controls age specific expression of $\mathrm{GnRH}$, developmental epigenetic regulation of the GnRH promoter driven SV40 transgene may underlie the difference in stage of tumor initiation between GN and GT1 cell lines.
} 
Similar to the findings of Mellon and colleagues comparing GnRH gene promoter structure of immature and mature cell lines, Lomniczi et al. (2013) recently reported that the female rat pubertal transition is accompanied by increased prevalence of activating histone PTMs at the kisspeptin promoter. Specifically, prior to puberty onset, the kisspeptin promoter was associated with a bivalent domain (i.e., H3K27me3 and H3K4me3) and occupied by a component of a polycomb repressive complex, EED. The transition to puberty was accompanied by decreased EED occupancy of the kisspeptin promoter, a gradual loss of the repressive H3K27me3 PTM, and increased levels of the permissive H3K9,14 acetylation and $\mathrm{H} 3 \mathrm{~K} 4 \mathrm{me} 3 \mathrm{PTM}$. The authors suggest this process is the consequence of increased DNA methylation of the EED promoter, leading to lower EED expression and consequential decreased occupancy of the kisspeptin promoter by the repressive PRC2 (EED, SUZ12, Ezh2) complex. These conclusions were largely based on observations of dramatically delayed puberty in female mice when DNA methylation was inhibited by peripheral administration of the pharmacological DNA-methyltransferase inhibitor 5-azacytidine (5-aza). While the conclusions are consistent with the observations, this 5-aza activity may not be specific to inhibition of post mitotic neuronal DNA methylation. Because the well-characterized mechanism of 5-aza requires nucleoside incorporation into DNA (Schermelleh et al., 2005; Stresemann and Lyko, 2008; Svedruzic, 2008) the mechanism of DNMT inhibition in post mitotic cells by this compound remains unclear. In addition, a significant reduction in growth rate and elevated levels of plasma corticosterone after the initiation of drug treatment (Lomniczi et al., 2013) is indicative of toxicities that likely contribute to delays in maturation. Because of these concerns, more direct approaches (e.g., cell specific genetic or enzyme expression manipulations) will be necessary to clarify the relationship between DNA methylation, chromatin modifications, and puberty onset. Nonetheless, these studies are instrumental to the notion that structural modification of bivalent promoters in the neuroendocrine hypothalamus is an integral step toward puberty onset and reproductive function.

Lomniczi and colleagues' focused approach toward measuring histone modification status across development at one gene has tremendous value for clarifying the temporal progression of bivalent promoter transactivation. Importantly, they report that permissive histone PTMs (H3K4me3 and H3K9,14 acetylation) accumulate near the kisspeptin promoter during the transition from juvenile to early pubertal stages. This preceded loss of the repressive $\mathrm{H} 3 \mathrm{~K} 27 \mathrm{me} 3 \mathrm{PTM}$, suggesting that recruitment of activating complexes is imperative for transactivation and increased gene expression. Interestingly, a recent discovery points to Tet enzymes as critical mediators of activation at bivalent promoters during neuronal differentiation. Specifically, while Ezh2 (the $\mathrm{H} 3 \mathrm{~K} 27$ methyltransferase component of PRC2) is critical for progression of neuronal precursor cells toward a neuronal fate, Tet2 or Tet3 appear to complete the process of differentiation. In fact, these studies also found that accumulation of intragenic 5hydroxymethylcytosine is associated with loss of H3K27me3 near regions with the most significant gene activation during neuronal differentiation. In addition, Tet 2 was recently reported to promote $\mathrm{H} 3 \mathrm{~K} 4 \mathrm{me} 3$ through association with the Set1/COMPASS complex (Deplus et al., 2013). The increasing H3K9,14 acetylation likely indicate RNA Polymerase II associated acetyltransferase (e.g., p300, CBP, PCAF, Gcn5) activity. Though it is possible that this PTM also directs the establishment or maintenance of Tet mediated $\mathrm{H} 3 \mathrm{~K} 4$ methylation as $\mathrm{H} 3 \mathrm{~K} 9,14$ acetylation attracts $14-$ 3-3 (Winter et al., 2008), a Tet2 interacting partner (Deplus et al., 2013).

In addition to activation, shifting chromatin structures also enable maintenance or deeper repression at some bivalent promoters across development; for example, neuronal lineage development depends on Jarid1b, which strips H3K4 methylation, consequently repressing bivalent promoters (Schmitz et al., 2011). The histone lysine demethylase, LSD1, has a similar role in chromatin modification, demethylating both di- and monomethylated H3K4. Importantly, recent preliminary studies (Gill et al., 2012a) found that heterozygous LSD1 knockout female mice exhibit precocious vaginal opening and first ovulation (3-4 days prior to wild-type littermates) with early elevations of plasma gonadotropins and hypothalamic expression of the puberty related gene, tac2 (neurokinin B; Gill et al., 2012b). These findings are analogous to those of Lomniczi et al. (2013), in that lower expression of an epigenetic repressive enzyme is related to elevated hypothalamic expression of a puberty related gene. However, LSD1 expression or activity changes across typical development are currently unknown. In addition, LSD1 also stimulates hormone (ligand associated androgen receptor) mediated gene activation through demethylation of H3K9 (Metzger et al., 2005). Consequently, while preliminary evidence suggests the intriguing possibility that LSD1 directly alters hypothalamic development (including GnRH and kisspeptin neurons) during the pubertal transition, models for cell or region specific genetic manipulations will be necessary to verify this interpretation. These models will be critical for determining the primary activity of LSD1 (i.e., H3K4 or H3K9 demethylation) as it relates to $\mathrm{GnRH}$ circuit development and reproductive maturation.

\section{CONCLUSION}

Our understanding of epigenetic regulation of GnRH neurons and neuroendocrine function in general is in its infancy, though the three reports detailed in this review indicate the importance of a shifting epigenetic structure at genes responsible for the development of reproductive function. Presently, DNA methylation and histone modifications both appear to influence levels of $\mathrm{GnRH}$ gene expression through neuronal maturation. On the other hand, kisspeptin gene expression appears most heavily influenced by histone modifications alone in the developing postnatal hypothalamus (Semaan et al., 2012; Tomikawa et al., 2012; Semaan and Kauffman, 2013). Importantly, a similar histone signature (i.e., bivalent domain) seems integral to the development of $\mathrm{GnRH}$ and kisspeptin neurons. Specifically, evidence is mounting that activation of a bivalent promoter (Lomniczi et al., 2013) and maintenance of a permissive chromatin state (Iyer et al., 2011) play crucial roles in pubertal maturation and $\mathrm{GnRH}$ neuronal function, respectively. Presently, the activating component is not characterized, though evidence points to a Tet enzyme (Kurian and Terasawa, 2012) complex. Decreasing expression or activity of 
repressive epigenetic enzymes (i.e., PRC2 components or LSD1) may also have a significant role in promoter structure and gene activation in the developing hypothalamus. How these activating and repressive complexes are directed to specific promoters and whether shifts in genomic localization are critical to $\mathrm{GnRH}$ circuit development and function remains to be determined. Nonetheless, with these targets to investigate, an understanding of GnRH neuron biology and the means by which an environment

\section{REFERENCES}

Azuara, V., Perry, P., Sauer, S., Spivakov, M., Jørgensen, H. F., John, R. M., et al. (2006). Chromatin signatures of pluripotent cell lines. Nat. Cell Biol. 8, 532-538. doi:10.1038/ ncb1403

Banks, G. C., Deterding, L. J., Tomer, K. B., and Archer, T. K. (2001). Hormone-mediated dephosphorylation of specific histone $\mathrm{Hl}$ isoforms. J. Biol. Chem. 276, 36467-36473. doi:10.1074/jbc.M104641200

Bernstein, B. E., Mikkelsen, T. S., Xie, X., Kamal, M., Huebert, D. J., Cuff, J., et al. (2006). A bivalent chromatin structure marks key developmental genes in embryonic stem cells. Cell 125, 315-326. doi:10.1016/j.cell.2006.02.041

Bestor, T., Laudano, A., Mattaliano, R., and Ingram, V. (1988). Cloning and sequencing of a cDNA encoding DNA methyltransferase of mouse cells. The carboxyl-terminal domain of the mammalian enzymes is related to bacterial restriction methyltransferases. J. Mol. Biol. 203, 971-983. doi:10.1016/0022-2836(88)90122-2

Bestor, T. H., and Ingram, V. M. (1983). Two DNA methyltransferases from murine erythroleukemia cells: purification, sequence specificity, and mode of interaction with DNA. Proc. Natl. Acad. Sci. U.S.A. 80, 5559-5563. doi:10.1073/pnas.80.18.5559

Branco, M. R., Ficz, G., and Reik, W. (2012). Uncovering the role of 5-hydroxymethylcytosine in the epigenome. Nat. Rev. Genet. 13, 7-13.

Clark, M. E., and Mellon, P. L. (1995). The POU homeodomain transcription factor Oct-1 is essential for activity of the gonadotropinreleasing hormone neuron-specific enhancer. Mol. Cell. Biol. 15, 6169-6177.

Constantin, S., Caraty, A., Wray, S., and Duittoz, A. H. (2009). Development of gonadotropinreleasing hormone-1 secretion in mouse nasal explants. Endocrinology 150, 3221-3227. doi:10.1210/en.2008-1711
Dawlaty, M. M., Breiling, A., Le, T., Raddatz, G., Barrasa, M. I., Cheng, A. W., et al. (2013). Combined deficiency of Tet1 and Tet2 causes epigenetic abnormalities but is compatible with postnatal development. Dev. Cell 24, 310-323. doi:10.1016/j.devcel.2012.12.015

Dawlaty, M. M., Ganz, K., Powell, B. E., Hu, Y. C., Markoulaki, S., Cheng, A. W., et al. (2011). Tetl is dispensable for maintaining pluripotency and its loss is compatible with embryonic and postnatal development. Cell Stem Cell 9, 166-175. doi:10.1016/j.stem.2011. 07.010

Deaton, A. M., and Bird, A. (2011). CpG islands and the regulation of transcription. Genes Dev. 25, 1010-1022. doi:10.1101/gad.2037511

Deplus, R., Delatte, B., Schwinn, M. K., Defrance, M., Méndez, J., Murphy, N., et al. (2013). TET2 and TET3 regulate GlcNAcylation and $\mathrm{H} 3 \mathrm{~K} 4$ methylation through OGT and SET1/COMPASS. EMBO J. 32, 645-655. doi:10.1038/emboj.2012.357

El Majdoubi, M., Sahu, A., Ramaswamy, S., and Plant, T. M. (2000). Neuropeptide Y: a hypothalamic brake restraining the onset of puberty in primates. Proc. Natl. Acad. Sci. U.S.A. 97, 6179-6184. doi:10.1073/pnas.090099697

Fueshko, S., and Wray, S. (1994). LHRH cells migrate on peripherin fibers in embryonic olfactory explant cultures: an in vitro model for neurophilic neuronal migration. Dev. Biol. 166, 331-348. doi:10.1006/dbio.1994.1319

Gardiner-Garden, M., and Frommer, M. (1987). CpG islands in vertebrate genomes. J. Mol. Biol. 196, 261-282. doi:10.1016/0022-2836(87)90689-9

Gill, J. C., Kwong, C., Clark, E., Carroll, R. S., Shi, Y. G., and Kaiser, U. B. (2012a). A role for the histobe demethylase LSD1 in controlling the timing of pubertal onset. Endocr. Soc. 33, OR12-1.

Gill, J. C., Navarro, V. M., Kwong, C., Noel, S. D., Martin, C., Xu, S., et al. (2012b). Increased neurokinin B (Tac2) expression in the mouse arcuate nucleus is an

modifies neuronal function (i.e., epigenetic modifications), lies at our fingertips.

\section{ACKNOWLEDGMENTS}

The authors are supported by National Institute of Health grants: R01HD11355 and R01HD15433 to Ei Terasawa and K99ES020878 to Joseph R. Kurian. Wisconsin National Primate Research Center grants P51OD011106/P51RR000167 also supported this work.

early marker of pubertal onset with differential sensitivity to sex steroidnegative feedback than Kiss1. Endocrinology 153, 4883-4893. doi:10.1210/en.2012-1529

Glaser, S., Schaft, J., Lubitz, S., Vintersten, K., van der Hoeven, F., Tufteland, K. R., et al. (2006). Multiple epigenetic maintenance factors implicated by the loss of Mll2 in mouse development. Development 133, 1423-1432. doi:10.1242/dev.02302

Hahn, M. A., Qiu, R., Wu, X. Li, A. X., Zhang, H., Wang, J. et al. (2013). Dynamics of 5hydroxymethylcytosine and chromatin marks in mammalian neurogenesis. Cell Rep. 3, 291-300. doi:10.1016/j.celrep.2013.01.011

Hermann, A., Goyal, R., and Jeltsch, A. (2004). The Dnmt1 DNA-(cytosineC5)-methyltransferase methylates DNA processively with high preference for hemimethylated target sites. J. Biol. Chem. 279, 48350-48359. doi:10.1074/jbc.M403427200

Iyer, A. K., Brayman, M. J., and Mellon, P. L. (2011). Dynamic chromatin modifications control GnRH gene expression during neuronal differentiation and protein kinase $\mathrm{C}$ signal transduction. Mol. Endocrinol. 25, 460-473. doi:10.1210/me.20100403

Kepa, J. K., Spaulding, A. J., Jacobsen, B. M., Fang, Z., Xiong, X., Radovick, S., et al. (1996a). Structure of the distal human gonadotropin releasing hormone (hGnrh) gene promoter and functional analysis in Gt1-7 neuronal cells. Nucleic Acids Res. 24, 3614-3620. doi:10.1093/nar/24.18.3614

Kepa, J. K., Jacobsen, B. M., Boen, E. A., Prendergast, P., Edwards, D. P., Takimoto, G., et al. (1996b). Direct binding of progesterone receptor to nonconsensus DNA sequences represses rat GnRH. Mol. Cell. Endocrinol. 117, 27-39. doi:10.1016/0303-7207(95) 03723-3

Kepa, J. K., Wang, C., Neeley, C. I., Raynolds, M. V., Gordon, D. F., Wood, W. M., et al. (1992). Structure of the rat gonadotropin releasing hormone ( $\mathrm{rGnRH})$ gene promoter and functional analysis in hypothalamic cells. Nucleic Acids Res. 20, 1393-1399. doi:10.1093/nar/20.6.1393

Kurian, J. R., Keen, K. L., and Terasawa, E. (2010). Epigenetic changes coincide with in vitro primate $\mathrm{GnRH}$ neuronal maturation. Endocrinology 151, 5359-5368. doi:10.1210/en.2010-0555

Kurian, J. R., and Terasawa, E. (2012) Elevated methylcytosine dioxygenase (Tet1) levels stimulate GnRH gene expression in immature neurons. Abstracts for the Society of Behavioral Neuroendocrinology Meeting, Madison, Number O.62.

Kurian, J. R., Kapke, J. A., and Terasawa, E. (2011). Epigenetic contribution to $\mathrm{GnRH}$ neuronal development in male pubertal development. Abstracts for the Society for Neuroscience Meeting, Washington, Number 500.03.

Lee, S. Y., Lau, A. T., Jeong, C. H., Shim, J. H., Kim, H. G., Kim, J., et al. (2010). Histone XH2AX is required for Xenopus anterior neural development: critical role of threonine 16 phosphorylation. J. Biol. Chem. 285, 29525-29534. doi:10.1074/jbc.M110.127233

Li, E., Bestor, T. H., and Jaenisch, R. (1992). Targeted mutation of the DNA methyltransferase gene results in embryonic lethality. Cell 69, 915-926. doi:10.1016/0092-8674(92)90611-F

Lomniczi, A., Loche, A., Castellano, J. M., Ronnekleiv, O. K., Bosch, M., Kaidar, G., et al. (2013). Epigenetic control of female puberty. Nat. Neurosci. 16, 281-289. doi:10.1038/nn.3319

Maurer, J. A., and Wray, S. (1997). Luteinizing hormone-releasing hormone (LHRH) neurons maintained in hypothalamic slice explant cultures exhibit a rapid LHRH mRNA turnover rate. J. Neurosci. 17, 9481-9491.

Mehlmann, L. M. (2005). Stops and starts in mammalian oocytes: recent advances in understanding the regulation of meiotic arrest and oocyte maturation. Reproduction 30, 791-799. doi:10.1530/rep.1.00793 
Mellon, P. L., Windle, J. J., Goldsmith, P. C., Padula, C. A., Roberts, J. L., and Weiner, R. I. (1990). Immortalization of hypothalamic GnRH neurons by genetically targeted tumorigenesis. Neuron 5, 1-10. doi:10.1016/0896-6273(90)90028-E

Metzger, E., Wissmann, M., Yin, N., Müller, J. M., Schneider, R., Peters, A. H., et al. (2005). LSD1 demethylates repressive histone marks to promote androgen-receptor-dependent transcription. Nature 437, 436-439.

Moore, J. P. Jr., and Wray, S. (2000). Luteinizing hormone-releasing hormone biosynthesis and secretion in embryonic LHRH neurons. Endocrinology 141, 4486-4495. doi:10.1210/en.141.12.4486

Okano, M., Bell, D. W., Haber, D. A., and Li, E. (1999). DNA methyltransferases Dnmt3a and Dnmt3b are essential for de novo methylation and mammalian development. Cell 99, 247-257. doi:10.1016/S00928674(00)81656-6

Okano, M., Xie, S., and Li, E. (1998). Cloning and characterization of a family of novel mammalian DNA (cytosine-5) methyltransferases. Nat. Genet. 19, 219-220. doi:10.1038/890

Pan, G., Tian, S., Nie, J., Yang, C., Ruotti, V., Wei, H., et al. (2007). Whole-genome analysis of histone H3 lysine 4 and lysine 27 methylation in human embryonic stem cells. Cell Stem Cell 1, 299-312. doi:10.1016/j.stem.2007.08.003

Pasini, D., Bracken, A. P., Hansen, J. B., Capillo, M., and Helin, K. (2007). The polycomb group protein Suz12 is required for embryonic stem cell differentiation. Mol. Cell. Biol. 27, 3769-3779. doi:10.1128/MCB.01432-06

Quanbeck, C., Sherwood, N. M., Millar, R. P., and Terasawa, E. (1997). Two populations of luteinizing hormone-releasing hormone neurons in the forebrain of the rhesus macaque during embryonic development. J. Comp. Neurol. 380, 293-309. doi:10.1002/(SICI) 10969861(19970414)380:3<293::AIDCNE1 > 3.0.CO;2-Y

Radovick, S., Wray, S., Lee, E., Nicols, D. K., Nakayama, Y.,
Weintraub, B. D., et al. (1991). Migratory arrest of gonadotropinreleasing hormone neurons in transgenic mice. Proc. Natl. Acad. Sci. U.S.A. 88, 3402-3406. doi:10.1073/pnas.88.8.3402

Ronnekleiv, O. K., and Resko, J. A. (1990). Ontogeny of gonadotropinreleasing hormone-containing neurons in early fetal development of rhesus macaques. Endocrinology 126, 498-511. doi:10.1210/endo126-1-498

Schermelleh, L., Spada, F., Easwaran, H. P., Zolghadr, K., Margot, J. B., Cardoso, M. C., et al. (2005). Trapped in action: direct visualization of DNA methyltransferase activity in living cells. Nat. Methods 2, 751-756. doi:10.1038/nmeth794

Schmitz, S. U., Albert, M., Malatesta, M., Morey, L., Johansen, J. V., Bak, M., et al. (2011). Jarid1b targets genes regulating development and is involved in neural differentiation. EMBO J. 30, 4586-4600. doi:10.1038/emboj.2011.383

Semaan, S. J., Dhamija, S., Kim, J., Ku, E. C., and Kauffman, A. S. (2012). Assessment of epigenetic contributions to sexually-dimorphic Kiss1 expression in the anteroventral periventricular nucleus of mice. Endocrinology 153, 1875-1886. doi:10.1210/en.2011-1975

Semaan, S. J., and Kauffman, A. S. (2013). Emerging concepts on the epigenetic and transcriptional regulation of the Kiss1 gene. Int. J. Dev. Neurosci. doi:10.1016/j.ijdevneu.2013.03.006. [Epub ahead of print]

Shen, X., Liu, Y., Hsu, Y. J., Fujiwara, Y., Kim, J., Mao, X., et al. (2008). EZH1 mediates methylation on histone $\mathrm{H} 3$ lysine 27 and complements EZH2 in maintaining stem cell identity and executing pluripotency. Mol. Cell 32, 491-502. doi:10.1016/j.molcel.2008.10.016

Stresemann, C., and Lyko, F. (2008). Modes of action of the DNA methyltransferase inhibitors azacytidine and decitabine. Int. J. Cancer 123, 8-13. doi:10.1002/ijc.23607

Suberbielle, E., Sanchez, P. E., Kravitz, A. V., Wang, X., Ho, K., Eilertson, K., et al. (2013). Physiologic brain activity causes DNA double-strand breaks in neurons, with exacerbation by amyloid- $\beta$. Nat. Neurosci. 16 , 613-621. doi:10.1038/nn.3356.

Svedruzic, Z. M. (2008). Mammalian cytosine DNA methyltransferase Dnmt1: enzymatic mechanism, novel mechanism-based inhibitors, and RNA-directed DNA methylation. Curr. Med. Chem. 15, 92-106. doi:10.2174/092986708783330700

Terasawa, E., Busser, B. W., Luchansky, L. L., Sherwood, N. M., Jennes, L., Millar, R. P., et al. (2001). Presence of luteinizing hormone-releasing hormone fragments in the rhesus monkey forebrain. J. Comp. Neurol. 439, 491-504. doi:10.1002/cne.1364

Terasawa, E., Keen, K. L., Mogi, K., and Claude, P. (1999). Pulsatile release of luteinizing hormonereleasing hormone (LHRH) in cultured LHRH neurons derived from the embryonic olfactory placode of the rhesus monkey. Endocrinology 140, 1432-1441. doi:10.1210/en.140. 3.1432

Terasawa, E., Quanbeck, C. D., Schulz, C. A., Burich, A. J., Luchansky, L. L., and Claude, P. (1993). A primary cell culture system of luteinizing hormone releasing hormone (LHRH) neurons derived from fetal olfactory placode in the rhesus monkey. Endocrinology 133, 2379-2390. doi:10.1210/en.133.5.2379

Tomikawa, J., Uenoyama, Y., Ozawa, M., Fukanuma, T., Takase, K., Goto, T., et al. (2012). Epigenetic regulation of Kiss1 gene expression mediating estrogen-positive feedback action in the mouse brain. Proc. Natl. Acad. Sci. U.S.A. 109, 1294-1301. doi:10.1073/pnas.1114245109

Whyte, D. B., Lawson, M. A., Belsham, D. D., Eraly, S. A., Bond, C. T., Adelman, J. P., et al. (1995). A neuron-specific enhancer targets expression of the gonadotropin-releasing hormone gene to hypothalamic neurosecretory neurons. Mol. Endocrinol. 9, 467-477. doi:10.1210/me.9.4.467

Winter, S., Simboeck, E., Fischle, W. Zupkovitz, G., Dohnal, I., Mechtler, K., et al. (2008). 14-3-3 proteins recognize a histone code at histone $\mathrm{H} 3$ and are required for transcriptional activation. $E M B O$ J. 27, 88-99. doi:10.1038/sj.emboj.7601954

Wray, S. (2010). From nose to brain: development of gonadotropin-releasing hormone1 neurones. J. Neuroendocrinol. 22, 743-753. doi:10.1111/j.13652826.2010.02034.x

Wu, S. C., and Zhang, Y. (2010). Active DNA demethylation: many roads lead to Rome. Nat. Rev. Mol. Cell Biol. 11, 607-620. doi:10.1038/nrm2950

Yagi, H., Deguchi, K., Aono, A., Tani, Y., Kishimoto, T., and Komori, T. (1998). Growth disturbance in fetal liver hematopoiesis of Mll-mutant mice. Blood 92, 108-117.

Yamaguchi, S., Hong, K., Liu, R., Shen, L., Inoue, A., Diep, D., et al. (2012). Tetl controls meiosis by regulating meiotic gene expression. Nature 492, 443-447. doi:10.1038/nature11709

Yu, B. D., Hess, J. L., Horning, S. E., Brown, G. A., and Korsmeyer, S. J. (1995). Altered Hox expression and segmental identity in Mllmutant mice. Nature 378, 505-508. doi:10.1038/378505a0

Conflict of Interest Statement: The authors declare that the research was conducted in the absence of any commercial or financial relationships that could be construed as a potential conflict of interest.

Received: 12 April 2013; accepted: 13 May 2013; published online: 27 May 2013.

Citation: Kurian JR and Terasawa E (2013) Epigenetic control of gonadotropin releasing hormone neurons. Front. Endocrinol. 4:61. doi: 10.3389/fendo.2013.00061

This article was submitted to Frontiers in Experimental Endocrinology, a specialty of Frontiers in Endocrinology.

Copyright $\odot 2013$ Kurian and Terasawa. This is an open-access article distributed under the terms of the Creative Commons Attribution License, which permits use, distribution and reproduction in other forums, provided the original authors and source are credited and subject to any copyright notices concerning any third-party graphics etc. 